\title{
Letter from...
}

\author{
Riccione
}

\section{Riccione Community Psychiatric Service}

\author{
Ermanno Arreghini, Assistant Psychiatrist; and Lidia Borghi, Assistant Psychiatrist, \\ Riccione Community Psychiatric Service (SIMAP) (address for correspondence: \\ Dr Lidia Borghi, SIMAP, Viale Fogazzaro 6, Riccione [Forli], Italy)
}

Your correspondents are two qualified psychiatrists in their early $30 \mathrm{~s}$, both with a strong communityorientated style of work, as our training had focused on the provision of care outside large hospitals. We work in Riccione Community Psychiatric Service.

Riccione is a summer resort in the north of Italy on the Adriatic 'riviera' in the Emilia-Romagna region, $100 \mathrm{~km}$ south of Bologna. It was developed in the 1870 s, and now has 35,000 inhabitants; its economy is largely centred on tourism.

Romagna, the southern part of the region, where Riccione is located, has never had a psychiatric hospital. Patients needing hospital treatment were admitted either to Imola Mental Hospital $(80 \mathrm{~km}$ to the north) or to Pesaro Mental Hospital $(20 \mathrm{~km}$ to the south), while community care was almost non-existent.

In the mid-1960s, a limited network of out-patient services was set up by the local health districts on the site of other medical clinics. No specific psychiatric facility was provided.

The Italian reform of psychiatric care, starting in 1978, changed many aspects of mental health care. Although much has been written about this 'revolution' (e.g. Crepet, 1988; Jones, 1988; De Girolamo, 1989), we would like to reiterate its main goals. These were:

(a) to shift the balance of psychiatric care from the old mental hospitals to the new community services

(b) to provide these new services with "intermediate facilities" (strutture intermedie) (Asioli, 1986) such as day hospitals, mental health centres, sheltered and other flats and work cooperatives as an alternative to hospital admission for both chronic and acute patients

(c) to run-down the old mental hospitals, by admitting all acute patients in need of inpatient care to psychiatric wards in general hospitals.

Every region is now divided into autonomous health districts (or USL, Unità Sanitaria Locale) and each provides a full network of health facilities, including primary care through GPs, social services and psychiatric care. The region of Emilia-Romagna has 41 USL areas; Riccione and its surroundings comprise USL 41, which therefore covers both urban and rural areas. The headquarters of the psychiatric service is in Riccione.

Our service covers all of USL 41, which comprises 14 municipalities and a total of 85,000 inhabitants. Besides the town of Riccione, our USL has two more municipalities along the coast, both of which depend on tourism. The strip along the coast is heavily populated and urbanised, while inland there are fewer inhabitants, who work mainly in agriculture.

This urban/rural divide has allowed us to make some interesting observations. For example, rural patients are much better adapted to living in their own homes. The physical distances between neighbours are great enough for patients to be able to avoid overly 'structured' activities, and they are often able to contribute to some degree to the agricultural work. This allows the rural patients to maintain a greater freedom, and they can more easily meet the needs of their own inner world.

Our psychiatric service comprises a main centre in Riccione, and three more minor centres (distretti) in the next three largest municipalities: Cattolica, Morciano and Coriano. The main centre is open 12 hours a day 7.30 a.m. to 7.30 p.m.), while the others are open three mornings a week. The daily routine covers consultations in the casualty departments, in other general hospital wards, and in nursing homes; domiciliary visits; out-patient services; and emergency duties. No Sunday or night services are provided and emergencies at these times are dealt with at the casualty department of the local general hospital.

Riccione has a semi-sheltered flat housing two chronic patients discharged from Imola Mental Hospital eight years ago, and a modern day hospital where drug treatment, rehabilitation activities and family therapy are available. The out-patient activity is the main resource and it comprises a number of 
different and flexible treatments ranging from a clinical approach (pharmacological and psychotherapeutic) to a more socially orientated one (provision of sheltered jobs, work in co-operatives, and residential communities).

Domiciliary visits are undertaken only when patients cannot or refuse to come to the clinic or in an emergency. This derives from the great importance we attribute to the patients' motivation, consent to treatment and autonomy. In convincing patients to attend our centres of their own accord, we limit any tendency to passivity and regression. This also establishes a suitable distance between patient and doctor, where the doctor is not seen as a controller, and the centres become a shelter where patients can come during either 'psychotic storms' or calmer periods.

The staff consists of 6 psychiatrists, 13 nurses, 3 social workers, 2 occupational therapists and 2 domestic assistants. Of these workers 1 psychiatrist, 4 nurses, 1 social worker and 2 occupational therapists are permanently based at the day hospital. Almost all have had an exclusively community-orientated training.

Riccione does not have a psychiatric ward and in case of need we rely mainly on the Cesena psychiatric ward at the general hospital $(35 \mathrm{~km}$ north of Riccione).

The psychiatric reform law of 1978 gave great importance to the concept of treating a patient, as far as possible, in his natural milieu. The law limits hos- pital admissions to those occasions when every other approach has failed. We have therefore never felt the need to open a psychiatric ward, but instead we decided to develop new intermediate facilities, such as the day hospital.

Our daily goal and challenge is to continue to work in this manner. We must maintain a tight network of contacts with our primary-care colleagues (especially GPs), local authorities and any other individuals who can contribute to our programmes of comprehensive care for our patients in the community.

\section{Acknowledgement}

We would like to thank Dr Daniela Ghigi, Head of Riccione Psychiatric Service, for her useful comments during the revision of the manuscript.

\section{References}

Asıolı, F. (1986) Un'esperienza di day-hospital. A talk given at the Atti del Convegno "Psichiatria e Strutture Intermedie: Autonoma e Dipendenza". Bologna, 17-19 novembre. Fogli di Informazione, 126, 48-55.

CREPET, P. (1988) The Italian mental health reform nine years on. Acta Psychiatrica Scandinavica, 77, 515-523.

DE GIROLAMO, G. (1989) Italian psychiatry and reform law: review of the international literature. International Journal of Social Psychiatry, 35, 21-37.

JONES, K. (1988) Experience in Mental Health: Community Care and Social Policy. London: Sage.

\section{Wisdom}

A short series of short pieces (with questions)

\section{Beginning}

“A poor man in an Eastern country travelling on foot along a road between towns spies something lying across his path and steps quickly back in alarm. He has mistaken the thin coiled object for a poisonous snake. It remains inert and, moving closer, the man sees what is in reality a piece of rope. The fear subsides. Pausing momentarily in reflection, realising that the rope will do to hold up his sagging trousers, the traveller picks it up and ties it with a smile of satisfaction around his middle before continuing on his journey."

This story is often told by Buddhist monks to beginners taking an interest in their teachings. The allegory is clear: the ideas you hear from us may sound strange and threatening at first, but if you examine them closely you will see that they are not only harm- less but could also prove useful ... just what you are looking for in fact.

Is it possible to study and so acquire wisdom? Perhaps. If so, is it not likely that some of the ideas presented to the student will seem strange and alarming at worst, useless or even ridiculous at best, in the beginning? Some teaching is required, and for the student curiosity, patience and perseverence, together with the use of a free and discerning mind.

If this is truly the case, a paradox has already arisen. Here is the chicken: wisdom. Here is the egg: a free and discerning mind. Which shall we choose to put first?

Aldrington House

LARRY CULLIFORD

Hove Community Mental Health Centre

Hove BN3 $4 A G$ 